\title{
Desenvolvimento sustentável no Brasil: uma análise textual dos fóruns de discussão
}

\section{Sustainable development in Brazil: a textual analysis of discussion forums}

Desarrollo sostenible en Brasil: análisis textual de los foros de discusión

Simone Yukimi Kunimoto ${ }^{1}$ Dany Rafael Fonseca Mendes ${ }^{2}$ Heitor Romero Marques ${ }^{3}$ Michel Constantino ${ }^{4}$

${ }^{1}$ Doutoranda em Administração na Universidade Federal de Mato Grosso do Sul (UFMS), e em Desenvolvimento Local na Universidade Católica Dom Bosco (UCDB). Mestre em Desenvolvimento Local pela UCDB. Administradora do KUMON, unidade Av. Mato Grosso. E-mail: simonekunimoto@gmail.com, ORCID: http://orcid.org/0000-0003-0952-7725

${ }^{2}$ Doutorando em Direito na Centro Universitário de Brasília (UNICEUB). Docente na UNICEUB. E-mail: rafael.dany@gmail.com, ORCID: http://orcid.org/0000-0002-2504-3272

${ }^{3}$ Doutor em Desarrollo Local Y Planteamiento Territorial pela Universidad Complutense de Madrid. Docente na Universidade Católica Dom Bosco (UCDB) na graduação e na pós-graduação. E-mail: heiroma@ucdb.br, ORCID: http://orcid.org/0000-0003-0093-1617

${ }^{4}$ Doutor em Economia pela Universidade Católica de Brasília (UCB). Docente na Universidade Católica Dom Bosco (UCDB). E-mail: michel@ucdb.br, ORCID: http://orcid.org/0000-0003-2570-0209 
Resumo: O desequilíbrio da relação entre o ser humano e o ambiente tem gerado discussões mundiais sobre o futuro do planeta, dando origem, a partir da década de 1970, a diversos fóruns globais de discussão. Sob a coordenação da Organização das Nações Unidas (ONU), as discussões sobre o tema foram avançando e, baseadas nos Objetivos de Desenvolvimento do Milênio (ODM), deram origem aos Objetivos de Desenvolvimento Sustentável (ODS). Em uma conjuntura com vistas à década de 2030, a presente pesquisa tem por objetivo investigar se o contexto brasileiro, notadamente com relação à atividade legislativa do País, está alinhado aos discursos contemporâneos de Desenvolvimento Sustentável (DS), partindo do mapeamento do conceito de DS no mundo e no Brasil, com utilização, também, do método de análise Text Mining (TM). Este trabalho tem caráter exploratório e busca responder se o Brasil está alinhado ao desenvolvimento sustentável, tal como o DS é defendido nos fóruns de discussão mundial, por meio da análise do arcabouço legal brasileiro. Os resultados apresentaram evidências de que, legalmente, o Brasil incorporou os avanços obtidos na discussão sobre o tema ao longo dos diferentes momentos históricos. Isso pode ser notado a partir da análise do arcabouço legal brasileiro, inclusive integrando a Carta Magna como marco decisivo, caracterizando a legislação do País sobre o assunto como uma das mais completas do mundo.

Palavras-chave: desenvolvimento; sustentabilidade ambiental; leis; mineração de texto.

Abstract: The imbalance of the relationship between the human being and the environment has generated worldwide discussions about the future of the planet, giving rise to several global discussion forums since the 1970s. Under the coordination of the United Nations (UN), discussions on the subject have progressed and, based on the Millennium Development Goals (MDG), have given rise to the Sustainable Development Goals (SDG). In a conjuncture with a view to the 2030s, this research aims to investigate whether the Brazilian context, especially concerning the country's legislative activity, is in line with the contemporary discourses of Sustainable Development (SD), starting with the mapping of the concept of SD in the world and Brazil, using, also, the Text Mining (TM) method of analysis. This work has an exploratory character and seeks to answer if Brazil is aligned with sustainable development, as the DS is defended in the forums of worldwide discussion, through the analysis of the Brazilian legal framework. The results presented evidences that, legally, Brazil incorporated the advances obtained in the discussion on the theme throughout the different historical moments. This can be seen from the analysis of the Brazilian legal framework, including integrating the Magna Carta as a decisive landmark, characterizing the country's legislation on the subject as one of the most complete in the world.

Keywords: development; environmental sustainability; law; text mining.

Resumen: El desequilibrio de la relación entre el ser humano y el ambiente ha generado discusiones mundiales sobre el futuro del planeta, dando origen, a partir de la década de 1970, a diversos foros globales de discusión. Bajo la coordinación de la Organización de las Naciones Unidas (ONU), las discusiones sobre el tema se avanzaron y, basadas en los Objetivos de Desarrollo del Milenio (ODM), dieron origen a los Objetivos de Desarrollo Sostenible (ODS). En una coyuntura con vistas a la década de 2030, la presente investigación tiene por objetivo investigar si el contexto brasileño, notadamente con relación a la actividad legislativa del país, está alineado a los discursos contemporáneos de Desarrollo Sostenible (DS), partiendo del mapeo del concepto de DS en el mundo y en Brasil, con la utilización, también, del método de análisis Text Mining (TM). Este trabajo tiene carácter exploratorio y busca responder si Brasil está alineado al desarrollo sostenible, tal como el DS es defendido en los foros de discusión mundial, a través del análisis del marco legal brasileño. Los resultados presentaron evidencias que, legalmente, Brasil incorporó los avances obtenidos en la discusión sobre el tema a lo largo de los diferentes momentos históricos. Esto puede ser notado a partir del análisis del marco legal brasileño, incluso integrando la Carta Magna como marco decisivo, caracterizando la legislación del país sobre el asunto como una de las más completas del mundo.

Palabras clave: desarrollo; sostenibilidad del medio ambiente; leyes; mineralización de texto. 


\section{INTRODUÇÃO}

O presente artigo é resultado de uma pesquisa que procurou responder se o Brasil estaria alinhado ao desenvolvimento sustentável tal como é defendido nos fóruns de discussão mundial sobre o tema.

Pesquisas que abordam desenvolvimento sustentável e o planejamento de metas para países aumentaram exponencialmente nas últimas duas décadas, especialmente após a criação da Cúpula do Milênio pela Organização das Nações Unidas (ONU). A Cúpula, que atualmente contempla 189 nações e 23 organizações internacionais, afirma o comprometimento com uma série de objetivos e metas para a melhoria das condições de vida das populações mais pobres do planeta. Para a organização e o alcance dessas melhorias, a ONU formulou os Objetivos de Desenvolvimento do Milênio (ODM), os quais foram adotados com a proposta de promover uma abordagem global e uma estratégia coordenada pela promoção da dignidade humana e pelo enfrentamento da degradação ambiental. Essas propostas foram adotadas por diversos países, os quais, desde então, promulgaram seus respectivos regulamentos internos para garantir a proteção humana e mitigação dos impactos ambientais.

Descrita como a capacidade de prover as necessidades sociais básicas, de forma que possam ser continuadas para o futuro indefinido, a sustentabilidade estabelece parâmetros para a busca do estado de bem-estar humano, relacionando-o ao compromisso com a preservação do meio ambiente. Nesta linha, a formulação de uma sociedade sustentável é associada à flexibilização dos parâmetros produtivos em relação à exploração do ecossistema, envolvendo a sociedade em suas atividades e não extrapolando as possibilidades de extração de recursos naturais.

Políticas governamentais foram utilizadas estrategicamente, num processo de ampliação permanente das liberdades substantivas dos indivíduos, em condições que estimulem a manutenção e a regeneração dos serviços prestados pelos ecossistemas às sociedades humanas. O que está em jogo nesse processo é o conteúdo da própria cooperação humana e a maneira como, no âmbito dessa cooperação, as sociedades optam por usar os ecossistemas do qual dependem. Em uma conjuntura com vistas 
à década de 2030, este estudo tem por objetivo investigar se o contexto brasileiro, notadamente com relação à atividade legislativa do País, está alinhado aos discursos contemporâneos de desenvolvimento sustentável, partindo do mapeamento do conceito de DS no mundo e no Brasil, com utilização, também, do método de análise Text Mining.

As normas de uma forma geral e políticas públicas nas distintas esferas de governo devem estar alinhadas à prosperidade, a fim de garantir a todas as pessoas plenas condições de vida, notadamente para o desfrute e a realização de uma vida próspera, como também para que o progresso, em sentido amplo, ocorra em harmonia com a natureza.

Particularmente no Brasil, a questão do desenvolvimento sustentável tem levado em conta tanto o meio ambiente em si quanto a produção agropecuária. Especialistas têm se debruçado nas pesquisas e na operacionalização da sustentabilidade muito no sentido de minorar os impactos da expansão agrícola sobre o meio ambiente.

Por ser o presente trabalho resultado de um estudo exploratório, o estado da arte valeu-se do Programa das Nações Unidas para o Desenvolvimento, nos estudos de Ramos et al., (2018) bem como nos de Pegorare et al. (2018), com o trabalho: Spatial econometric analysis of the main agricultural commodities produced in Central-West Region, Brazil, publicado no African Journal of Agricultural Research. Igualmente, constitui estado da arte o estudo de Branco (1989) intitulado: Ecossistêmica: Uma Abordagem Integrada dos Problemas do Meio Ambiente. Ademais, além da Constituição da República Federativa do Brasil, de 5 de outubro de 1988, diversas normas, entre leis e regulamentações ${ }^{5}$, seguem no mesmo sentido.

\footnotetext{
${ }^{5}$ Decreto n. 7.746/2012; Decreto n. 7.794/2012; Decreto n. 7.390/2010; Decreto n. 8.892/2016; Lei n. 6.766/1979; Lei n. 6.938/1981; Lei n. 7.347/1985; Lei n. 7.805/1989; Lei n. 8.666/1993; Lei n. 9.433/1997; Lei n. 9.605/1998; Lei n. 12.187/2009; Lei n. 12.305/2010; Lei n. 12.651/2012; Portaria n. 24/2017; e Portaria n. 81/2017.
} 


\section{DESENVOLVIMENTO SUSTENTÁVEL: DE ESTOCOLMO A NOVA IORQUE}

Além de influências advindas do Clube de Roma ${ }^{6}$, o debate sobre o desenvolvimento econômico sofreu uma importante inflexão a partir da Conferência das Nações Unidas sobre o Ambiente Humano, em junho de 1972. Pela primeira vez, a ONU deu eco às crescentes preocupações acerca do meio ambiente, e, já a partir do final da década de 1960, estas inquietações passaram a integrar a "consciência coletiva do mundo" (ONU, 2018). A declaração final da Conferência de 1972 inaugurou, em escala global, a agenda ambiental. O documento deixa claro, entre outros itens, que os baluartes do desenvolvimento deveriam ser revistos, pois a humanidade estava se dirigindo para um caminho sem volta, e uma mudança de direção exigia a participação de governos e pessoas:

A point has been reached in history when we must shape our actions throughout the world with a more prudent care for their environmental consequences. [...] To defend and improve the human environment for present and future generations has become an imperative goal for mankind - a goal to be pursued together with, and in harmony with, the established ad fundamental goals of peace and of world-wide economic and social development. [...] The Conference calls upon Governments and peoples to exert common efforts for the preservation and improvement of the human environment, for the benefit of all the people and for their prosperity (UNITED NATIONS, 1972, p. 3-4) ${ }^{7}$.

\footnotetext{
${ }^{6} \mathrm{O}$ Clube de Roma é um grupo de pessoas ilustres que se reúnem para debater um vasto conjunto de assuntos relacionados à política, economia internacional e, sobretudo, ao meio ambiente e desenvolvimento sustentável. Foi fundado em 1966 pelo industrial italiano Aurelio Peccei e pelo cientista escocês Alexander King. Tornou-se muito conhecido a partir de 1972, ano da publicação do relatório intitulado Os Limites do Crescimento.

${ }^{7}$ Um objetivo foi alcançado na história quando devemos moldar nossas ações em todo o mundo com um cuidado mais prudente com suas consequências ambientais [...]. Defender e melhorar o ambiente humano para as gerações presentes e futuras tornou-se um objetivo imperativo para a humanidade - uma meta a ser perseguida e harmonizada com os objetivos fundamentais e estabilizados da paz e do desenvolvimento econômico e social mundial. [...] A Conferência conclama os governos e povos a empenhar esforços comuns pela preservação e melhoria do meio ambiente humano, em benefício de todos os povos e por sua prosperidade.
} 
Logo em seguida, em dezembro do mesmo ano, a ONU criou o Programa das Nações Unidas para o Meio Ambiente. Trata-se de uma agência que exerce as funções de "alertar povos e nações sobre problemas e ameaças ao meio ambiente e recomendar medidas para melhorar a qualidade de vida da população sem comprometer os recursos e serviços ambientais das gerações futuras" (ONU, 1972, p. 3-4).

Mas foi em 1987 que os esforços ambientais ganharam o formato que se tornou predominante até o final da primeira década do século XXI. Em abril daquele ano, a Comissão Brundtland ${ }^{8}$ trouxe a público um conceito à época inovador: o desenvolvimento sustentável. O relatório desta Comissão, intitulado Nosso Futuro Comum, trouxe 21 pontos que tratavam da necessidade de uma nova abordagem para o crescimento econômico como um requisito essencial para a erradicação da pobreza e manutenção dos recursos naturais para as gerações futuras (UNITED NATIONS, 1987).

O legado proporcionado por Brundtland levou à formação mais sólida do pensamento desenvolvimentista mais responsável, que, apesar de seu rápido avanço em termos históricos, envolveu a comunidade internacional em torno de um mesmo propósito, independentemente do tamanho da economia de um determinado país ou mesmo de suas raízes culturais e históricas. Para iniciar um conjunto coordenado de esforços que levariam à compreensão equânime e abrangente do tema, planejamento de ações de intervenção no combate à pobreza, preservação ambiental e sua efetiva implementação, organizou-se a United Nation Conference on Environment and Development (Conferência das Nações Unidas sobre o Meio Ambiente e Desenvolvimento), realizada na cidade do Rio de Janeiro, em 1992.

Entre os dias 3 e 14 de junho daquele ano, a Conferência - que ficou conhecida como Rio-92, ou "The Earth Summit"9 (UNITED NATIONS, 1992b) - definiu os princípios fundamentais sobre o desenvolvimento sustentável, adotado pelas 178 nações participantes. Naquele evento, foram criadas duas

\footnotetext{
${ }^{8}$ Nome herdado da presidente da Comissão Mundial sobre o Meio Ambiente e Desenvolvimento, que elaborou o relatório, a médica e ex-primeira-ministra da Noruega, Gro Harlem Brundtland (ONU, 2018).

${ }^{9}$ Em português, adotando uma tradução livre, o termo significa "Cúpula da Terra".
} 
convenções - sobre biodiversidade ${ }^{10}$ e sobre mudanças climáticas ${ }^{11}$ - e três documentos: 1) Declaração do Rio sobre Meio Ambiente e Desenvolvimento; 2) Declaração de Princípios sobre Florestas; e 3) Agenda 21.

A primeira Declaração trouxe, logo em seu primeiro princípio, que "os seres humanos estão no centro das preocupações com o desenvolvimento sustentável. Têm direito a uma vida saudável e produtiva, em harmonia com a natureza" (ONU, 1992a). O documento, ao longo dos seus 27 princípios, demonstrou a preocupação dos governantes em relação ao então vigente padrão de desenvolvimento, buscando equalizar o entendimento do que seria a adoção de práticas exploratórias mais responsáveis.

Na segunda Declaração - Princípios sobre Florestas ${ }^{12}$-, a Assembleia Geral da Organização das Nações Unidas (ONU) realizou recomendações sobre a conservação e o manejo sustentável das florestas. O documento foi construído em torno de 15 princípios que tinham como propósito maior apontar um consenso sobre "a gestão, conservação e exploração sustentável de todos os tipos de florestas" (UNITED NATIONS, 1992a).

Já a Agenda 21 (CÂMARA DOS DEPUTADOS, 1995, p. 1) estabeleceu "uma abordagem equilibrada e integrada das questões relativas a meio ambiente e desenvolvimento", oferecendo um programa de trabalho que identificasse os "problemas prioritários, os recursos e meios para enfrentá- los e as metas para as próximas décadas" e que pudesse "disciplinar e concentrar esforços nas áreas-chave, evitando a dispersão, o desperdício e as ações contraproducentes" (p. 7). Segundo a ONU, a importância estratégica deste documento é que ele orienta ações mais abrangentes e que representam relações de causa e efeito em diversas áreas de ação:

A Agenda 21 foi além das questões ambientais para abordar os padrões de desenvolvimento que causam danos ao meio ambiente. Elas incluem: a pobreza e a dívida externa dos países em desenvolvimento;

\footnotetext{
${ }^{10}$ Convenção da ONU sobre a Diversidade Biológica (UNITED NATIONS, 2018a).

${ }^{11}$ Convenção da ONU de Combate à Desertificação (UNITED NATIONS, 2018b).

12 Trata-se do Anexo III do documento Report of the United Nations Conference on Environment and Development, cujo título é Non-legally binding authoritative statement of principles for a global consensus on the management, conservation and sustainable development of all types of forests (ONU, 1992a).
} 
padrões insustentáveis de produção e consumo; pressões demográficas e a estrutura da economia internacional. O programa de ação também recomendou meios de fortalecer o papel desempenhado pelos grandes grupos - mulheres, organizações sindicais, agricultores, crianças e jovens, povos indígenas, comunidade científica, autoridades locais, empresas, indústrias e ONGs - para alcançar o desenvolvimento sustentável (ONU, 2018 p. 13-14).

A ONU criou, como forma de oferecer acompanhamento e suporte para o atingimento dos objetivos da Agenda 21, a Comissão para o Desenvolvimento Sustentável (CDS), integrando o Conselho Econômico e Social das Nações Unidas (Ecosoc). A CDS coopera, desde a sua criação, "com os países para que atinjam os objetivos da Rio-92 e é uma das responsáveis pela organização das conferências da ONU que se realizam desde então" (SENADO FEDERAL, 2018b, p. 2).

Nos anos seguintes, uma série de eventos marcou a consolidação da Cúpula de 1992, trazendo diferentes contribuições para o desenvolvimento sustentável. Em 1997, a Cúpula da Terra +5 foi uma sessão especial para revisar e avaliar a implementação da Agenda 21. Recomendou a adoção de metas para reduzir as emissões de gases de efeito estufa, melhoria nos padrões de geração, distribuição e uso de energia, além de estabelecer a erradicação da pobreza como pré-requisito para o desenvolvimento sustentável. Dali se originou o Kyoto Protocol, em 11 de dezembro de 1997, que entraria em ação em 2005 (UNITED NATIONS, 2018d).

Em seguida, como a própria ONU destaca, uma série de conferências trouxe de modo mais ou menos explícito os princípios sobre o tema (ONU, 2018): Segunda Conferência da ONU sobre Assentamentos Humanos Istambul, 1999; Sessão Especial da Assembleia Geral sobre Pequenos Estados Insulares em Desenvolvimento - Nova Iorque, 1999; Cúpula do Milênio Nova lorque, 2000 -, na qual, em seu sétimo objetivo, fica clara a orientação para "garantir a sustentabilidade ambiental" (ONU, 2018, p. 12-16).

O ano de 2002 foi marcado pelo World Summit on Sustainable Development ${ }^{13}$, também conhecido como Rio+10, em Joanesburgo, na África do Sul, que realizou um "balanço das conquistas, desafios e das

${ }^{13}$ Em tradução livre: Cúpula Mundial sobre Desenvolvimento Sustentável. 
novas questões surgidas desde a Cúpula da Terra de 1992. Foi uma Cúpula de implementação, concebida para transformar as metas, promessas e compromissos da Agenda 21 em ações concretas e tangíveis" (ONU, 2018, p. 12-16). Em seguida, em 2005, a comunidade internacional realizou a revisão do Programa de Barbados das Nações Unidas, gerando o documento intitulado Estratégia de Maurício, que faz recomendações específicas sobre mudanças climáticas, desastres naturais e ambientais, recursos diversos, produção e consumo sustentável, além de temas como cultura, ciência e tecnologia (ONU, 2018, p. 19-21).

A Conferência de 1972 representou o marco inicial de toda a construção do conceito de desenvolvimento sustentável, que culminou, 40 anos depois, em uma nova Conferência na Cidade do Rio de Janeiro - a Rio+20. Se a Rio-92 representou o início de uma adoção equânime dos preceitos do que seria produzir de modo responsável, resguardando o planeta para as gerações futuras, a United Nations Conference on Sustainable Development, ocorrida entre os dias 20 e 22 de junho de 2012, significou um conjunto de importantes avanços.

Primeiramente, os estados participantes decidiram lançar um processo para desenvolver o que chamaram de Sustainable Development Goals $\mathrm{SDGs}^{14}$, alinhados aos Millennium Development Goals ${ }^{15}$, convergindo para a agenda de desenvolvimento que seria discutida no ano de 2015 (UNITED NATIONS, 2018c). O evento representou também a adoção de políticas para a chamada economia verde, e os governos participantes decidiram estabelecer estratégias para o financiamento das ações direcionadas a tais objetivos e fortalecer o United Nations Environment Programme (UNEP), programa voltado para o desenvolvimento. Outros avanços relevantes foram (UNITED NATIONS, 2018c):

a) Estabelecimento de um fórum político de alto nível para as questões de desenvolvimento sustentável;

b) Lançamento de um programa de trabalho na área de mensuração do progresso do crescimento nos produtos internos dos países

\footnotetext{
${ }^{14}$ Em tradução livre: Objetivos de Desenvolvimento Sustentável.

${ }^{15}$ Em tradução livre: Objetivos de Desenvolvimento do Milênio.
} 
para a melhoria nas tomadas de decisão;

c ) Adoção governamental de um quadro de programas sobre padrões sustentáveis de consumo e produção; e

d) Decisões em áreas temáticas diversas, como energia, segurança alimentar, oceanos, cidades, que culminaram na Third International Conference on Small Island Developing States - SIDS Conference, em 2014.

Mais de 700 compromissos voluntários e novas parcerias para a promoção do desenvolvimento sustentável foram firmados durante a Conferência, servindo como fonte de material, conceitos e informações para nortear a formação do pensamento e o estabelecimento de objetivos e metas factíveis e congruentes.

A segunda década do século XXI viu ser realizada, ainda em 2015, a Cúpula de Desenvolvimento Sustentável, na cidade de Nova lorque. Durante este encontro, os países da Organização das Nações Unidas definiram os ODS como parte de uma nova agenda de desenvolvimento sustentável que deve finalizar o trabalho dos Objetivos de Desenvolvimento do Milênio (ONU, 2018). Os trabalhos desta nova agenda - que recebe a alcunha de Agenda 2030 para o Desenvolvimento Sustentável - já se encontram em curso, tendo prazo previsto para o ano de 2030.

\section{LEGISLAÇÃO DE DESENVOLVIMENTO SUSTENTÁVEL NO BRASIL}

Nas discussões sobre o desenvolvimento associado ao equilíbrio ambiental, social e econômico, o Brasil desponta como referência. Sua atuação incisiva na Rio-92 influenciou de modo decisivo na aprovação de documentos norteadores globais, "como a Agenda 21, a Declaração do Rio sobre Ambiente e Desenvolvimento, a Declaração de Princípios sobre Florestas e as Convenções sobre Biodiversidade, Mudança Climática e Desertificação" (BRASIL, s.d.), tanto que é considerado pela própria ONU como uma "referência nas negociações globais sobre a agenda de desenvolvimento pós-2015" (ONU, 2014).

O País é uma grande referência mundial nas discussões sobre o desenvolvimento sustentável, seja por ter sediado dois dos mais relevantes 
encontros da ONU - Eco-92 e Rio+20 -, seja pela intervenção política na ONU, marcando seu posicionamento incisivo, ainda que este pudesse ser mais bem-sucedido nas negociações dentro da agenda de desenvolvimento pós-2015. Neste sentido, Paes (2018, p. 3-4) afirma, em sua pesquisa intitulada Estado da Arte da Discussão dos Objetivos de Desenvolvimento Sustentável no Brasil, que:

O Brasil tem defendido um posicionamento muito consistente com o resultado da Rio+20. Mas além da qualidade política da intervenção é preciso ter também qualidade técnica e, para isso, o governo precisa mobilizar todos os seus recursos internos para fazer uma intervenção de forma eficaz.

O estudo de Paes (2018) mostra ainda que o Brasil, embora seja "um ator influente", precisa construir um posicionamento de longo prazo, firmando acordos e orientando suas políticas de modo estratégico e perene: "O Brasil é importante, mas ele fica mais importante se tiver um posicionamento de país e não só do governo" (PAES, 2018). Pode-se inferir, portanto, que existe a possibilidade de que as políticas públicas voltadas para o desenvolvimento sustentável respondam mais a objetivos particulares de determinados governos do que a uma lógica mais estruturada.

Mas se deve avaliar de que forma o conceito sobre o desenvolvimento sustentável foi construído no Brasil e como ele se alinha ou não ao movimento maior determinado pelas conferências globais. A análise sobre a legislação brasileira acerca do tema pode oferecer elementos que permitam correlacionar cada momento histórico aos aspectos priorizados pelo legislador, refletindo os valores que foram sendo construídos desde a Conferência de Estocolmo em 1972, até a agenda pós-2015.

O levantamento da principal legislação sobre o tema no Brasil demonstra os principais marcos que levaram à construção sobre o conceito de desenvolvimento sustentável no país e demonstra, como já constava do Portal Brasil (BRASIL, 2010), que "As leis que tratam do meio ambiente no Brasil estão entre as mais completas e avançadas do mundo":

a) Lei n. 6.766, de 19 de dezembro de 1979 (BRASIL, 1979): Lei do Parcelamento do Solo Urbano. Proíbe loteamentos urbanos em áreas de preservação ecológicas, áreas de poluição e terrenos alagadiços. 
b) Lei n. 6.938, de 17 de janeiro de 1981 (BRASIL, 1981): Lei da Política Nacional do Meio Ambiente. Institui a Política Nacional do Meio Ambiente (PNAMA) e o Sistema Nacional do Meio Ambiente (SISNAMA). Institui a obrigatoriedade de estudos e relatórios de impacto ambiental, além de propor responsabilidade civil por danos ao meio ambiente.

c) Lei n. 7.347, de 24 de julho de 1985 (BRASIL, 1985): Lei da Ação Civil Pública. Responsabilização, por meio da ação civil pública, de danos provocados ao meio ambiente, consumidor, patrimônios artístico, turístico ou paisagístico.

d) Constituição da República Federativa do Brasil, de 1988. Art. 225 (BRASIL, 1988): Confere, pela primeira vez no país, um caráter de oficialidade para o tema do Desenvolvimento Sustentável. Ainda que não defina os termos de modo claro - o que só, de fato, ocorre na conferência Rio-92 - a Carta Magna traduz o pensamento contemporâneo ao seu momento histórico trazendo o mesmo entendimento das conferências internacionais.

e) Lei n. 7.805, de 18 de julho de 1989 (BRASIL, 1989): Lei da Exploração Mineral. Regula as atividades voltadas para o garimpo e exploração dos recursos minerais.

f) Lei n. 8.666, de 21 de junho de 1993 (BRASIL, 1993): Institui normas para a licitação e contratos da Administração Pública, com direcionamento para o desenvolvimento nacional sustentável.

g) Lei n. 9.433, de 8 de janeiro de 1997 (BRASIL, 1997): Lei de Recursos Hídricos. Cria o Sistema Nacional de Recursos Hídricos e institui a Política Nacional de Recursos Hídricos.

h) Lei n. 9.605, de 12 de fevereiro de 1998 (BRASIL, 1998): Lei dos Crimes Ambientais. Organiza e reordena infrações e punições da legislação ambiental brasileira, incluindo a possibilidade de responsabilização de pessoas jurídicas.

i) Lei n. 12.187, de 29 de dezembro de 2009 (BRASIL, 2009): institui a Política Nacional sobre Mudança do Clima (PNMC).

j) Decreto n. 7.390, de 9 de dezembro de 2010 (BRASIL, 2010a): Regulamenta a Política Nacional sobre Mudança do Clima (PNMC). 
Em seu Art. 60, está previsto que, para alcançar o compromisso nacional voluntário de que trata o Art. 12 da Lei n. 12.187/2009, serão implementadas ações que almejam a redução, entre 1,168 milhão de toneladas de CO2eq e 1,259 milhão de toneladas CO2eq, do total das emissões estimadas para o ano de 2020 (3,236 milhões de t CO2eq). Nesta projeção, o setor agropecuário tem a responsabilidade de contribuir com a redução de $22,5 \%$ dessas emissões.

k) Lei n. 12.305, de 2 de agosto de 2010 (BRASIL, 2010b): Lei da Política Nacional dos Resíduos Sólidos.

I) Lei n. 12.651, de 25 de maio de 2012 (BRASIL, 2012c): Novo Código Florestal Brasileiro. Estabelece normas gerais para a proteção de áreas e vegetação, além de estabelecer o uso ecologicamente sustentável de espécies vegetais.

m)Decreto n. 7.746, de 5 de junho de 2012 (BRASIL, 2012a): Regulamenta o Art. 3 da Lei n. 8.666, de 21 de junho de 1993, para estabelecer critérios e práticas para a promoção do desenvolvimento nacional sustentável nas práticas da administração pública.

n) Decreto n. 7.794, de 20 de agosto de 2012 (BRASIL, 2012b): Institui a Política Nacional de Agroecologia e Produção Orgânica. No texto do Decreto, no caput do Art. 1ำ, "Fica instituída a Política Nacional de Agroecologia e Produção Orgânica - PNAPO [...], contribuindo para o desenvolvimento sustentável e a qualidade de vida da população, por meio do uso sustentável dos recursos naturais e da oferta e consumo de alimentos saudáveis".

o) Decreto n. 8.892, de 27 de outubro de 2016 (BRASIL, 2016): Cria a Comissão Nacional para os Objetivos de Desenvolvimento Sustentável.

p) Portaria n. 24, de 4 de abril de 2017 (BRASIL, 2017b): Institui o Comitê de Seleção Pública para a escolha dos representantes da Comissão Nacional para os Objetivos de Desenvolvimento Sustentável.

q) Portaria n. 81, de 11 de outubro de 2017 (BRASIL, 2017a): Aprova o Regimento Interno da Comissão Nacional para os Objetivos de Desenvolvimento Sustentável. 
Os textos legais produzidos no Brasil se alinham, portanto, àquilo que se coloca, em cada momento histórico, como prioritário na discussão sobre o que é desenvolvimento sustentável dentro da comunidade internacional e, ainda, quais são os princípios que norteiam a discussão sobre o tema. 0 arcabouço legal brasileiro analisado evidencia o alinhamento entre o conceito em sua forma mais avançada e ordenamento jurídico no País.

\section{PROCEDIMENTOS METODOLÓGICOS}

Após o desenvolvimento dos estudos e textos legais analisados de forma exploratória nas seções 0 e 0, será realizado o procedimento de análise quantitativa, a partir da abordagem de similitude e do Dendrograma, os quais seguem uma lógica metodológica de Text Mining (TM). Segundo Tan (1999), TM é o processo de obtenção de informações importantes de bases textuais não estruturadas. É considerado um campo multidisciplinar, envolvendo recuperação de informação, análise de texto, extração de informação, clustering, classificação, visualização, banco de dados tecnológicos, machine learning e data mining. Na última década, o Text Mining vem sendo amplamente utilizado, tendo como base a estatística e o aprendizado de máquina, sendo o texto a informação de entrada (FEINERER; HORNIK; MEYER, 2008). De acordo com Dixon (1997), são quatro as etapas do TM: 1) identificação do problema, 2) pré-processamento, 3) mineração dos dados e 4) pós-processamento. Na análise que se seguirá (seção 0), serão utilizados os resumos dos artigos citados no texto das seções 0 e 0 , e as palavras serão agrupadas de acordo com suas características em comum, utilizando a técnica multivariada de análise de cluster (HAIR et al., 2009). O método agregador de similaridades também será empregado aqui, ou seja, uma função inversa da distância entre os objetos, possibilitando, assim, organizar o Dendrograma proposto (TAN, 1999). As medidas calculadas podem ser apresentadas de acordo com as palavras distribuídas num plano cartesiano, sendo a similaridade medida pelo inverso da distância euclidiana entre os pontos, qual seja: 


$$
\begin{aligned}
& d\left(p_{i}, p_{j}\right)=\text { distância entre palavras } i, j=\sqrt{\sum_{k=1}^{n}\left(y_{i k}-y_{j k}\right)^{2}} \\
& \xi\left(p_{i}, p_{j}\right)=\text { similaridade entre palavras } i, j=\frac{1}{\sqrt{\sum_{k=1}^{n}\left(y_{i k}-y_{j k}\right)^{2}}}
\end{aligned}
$$

Essa objetividade metodológica, embora vise à redução de distorções sobre os temas escolhidos para as publicações a respeito do desenvolvimento sustentável, permite avaliações objetivas sobre o tema proposto.

\section{RESULTADOS}

\subsection{Análise Exploratória}

O propósito deste estudo foi o de buscar uma correlação entre a conceituação e a prática de desenvolvimento sustentável dos textos e leis analisados. A hipótese inicial que, afinal, mostrou-se verdadeira, é que as atividades produtivas desenvolvidas no Brasil se harmonizam com as meIhores práticas contemporâneas de desenvolvimento sustentável defendidas nos principais fóruns de discussão global sobre o tema.

Foram analisados todos os relatórios finais das Conferências da Organização das Nações Unidas (ONU), desde o início do debate sobre desenvolvimento sustentável, em 1972, até o encontro mais recente à época da confecção do presente artigo, que culminou com a Agenda 2030 para o Desenvolvimento Sustentável. Este estudo permitiu traçar uma tendência histórica sobre as melhores práticas globais voltadas para o tema.

O levantamento do arcabouço legal brasileiro sobre sustentabilidade evidenciou a convergência entre as práticas sustentáveis globais e o ordenamento jurídico local. Por outro lado, foi possível estabelecer também uma forte correlação com os princípios do desenvolvimento local identificados durante o presente artigo. Foram prospectados, de 1979 até 2017, leis, decretos e outros instrumentos legais que versassem sobre o tema de sustentabilidade.

O estudo identificou dez leis, quatro decretos, duas portarias e a própria Constituição Federal Brasileira pautando o tema ao longo deste 
breve recorte histórico. Fato que levou à conclusão de que o legislador brasileiro sempre teve em mente a necessidade de conciliar as tendências contemporâneas sobre preservação ambiental, bem-estar social e progresso econômico - o que se convencionou chamar de tripé da sustentabilidade com as peculiares necessidades dos arranjos produtivos locais.

Por fim, foi possível inferir que, ainda que o Brasil ocupe uma posição de destaque internacional na defesa dos princípios sobre o desenvolvimento sustentável, inclusive caracterizando sua legislação sobre tais temas como das mais completas do mundo, a posição de protagonismo do país fica ameaçada por uma integração aquém do desejável com a comunidade internacional, notabilizando-se pela construção de políticas de governo, e não de Estado - que seriam mais desejáveis em função de seu caráter de longo prazo.

\subsection{Análise da mineração de texto}

A análise da matriz de distância apresentada na Figura 1 distribui os vários clusters dos textos analisados, nos quais palavras como "ambiental", "cúpula", "objetivo" e "princípio" são as mais frequentes e estão interligadas no quadrante de similaridade.

Os resultados estão de acordo com a descrição dos textos e comprovam evidências de que o Brasil segue os princípios defendidos nas últimas décadas pelas reuniões mundiais da cúpula do milênio. 
Figura 1 - Matriz de Distância

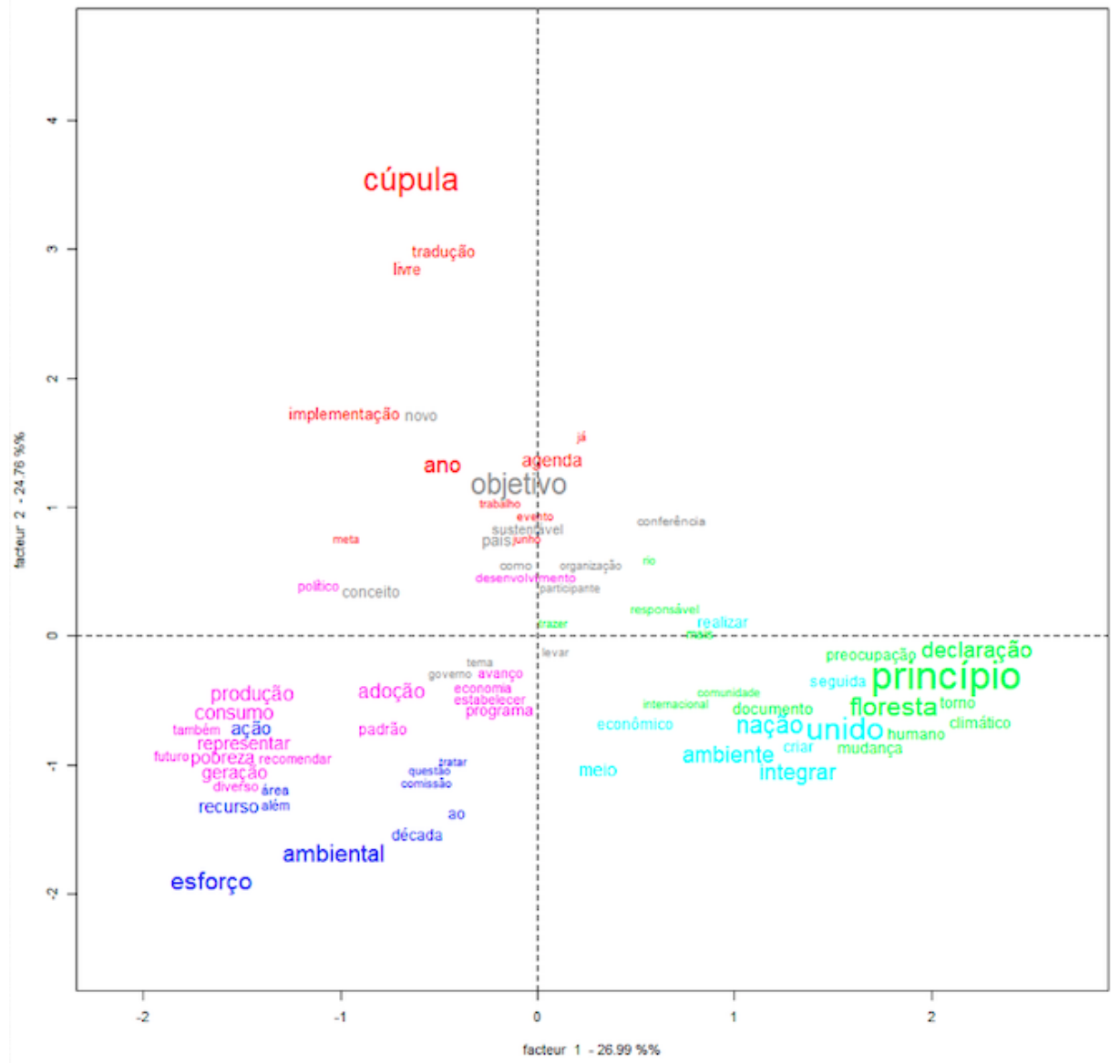

Fonte: Autoria própria.

A similaridade das palavras foi avaliada pela árvore apresentada na Figura n. 2, abaixo, que interliga as principais palavras com a palavra mais frequente, ou seja, mais importante, que é "desenvolvimento". 
Figura 2 - Árvore de Similitude de Palavras

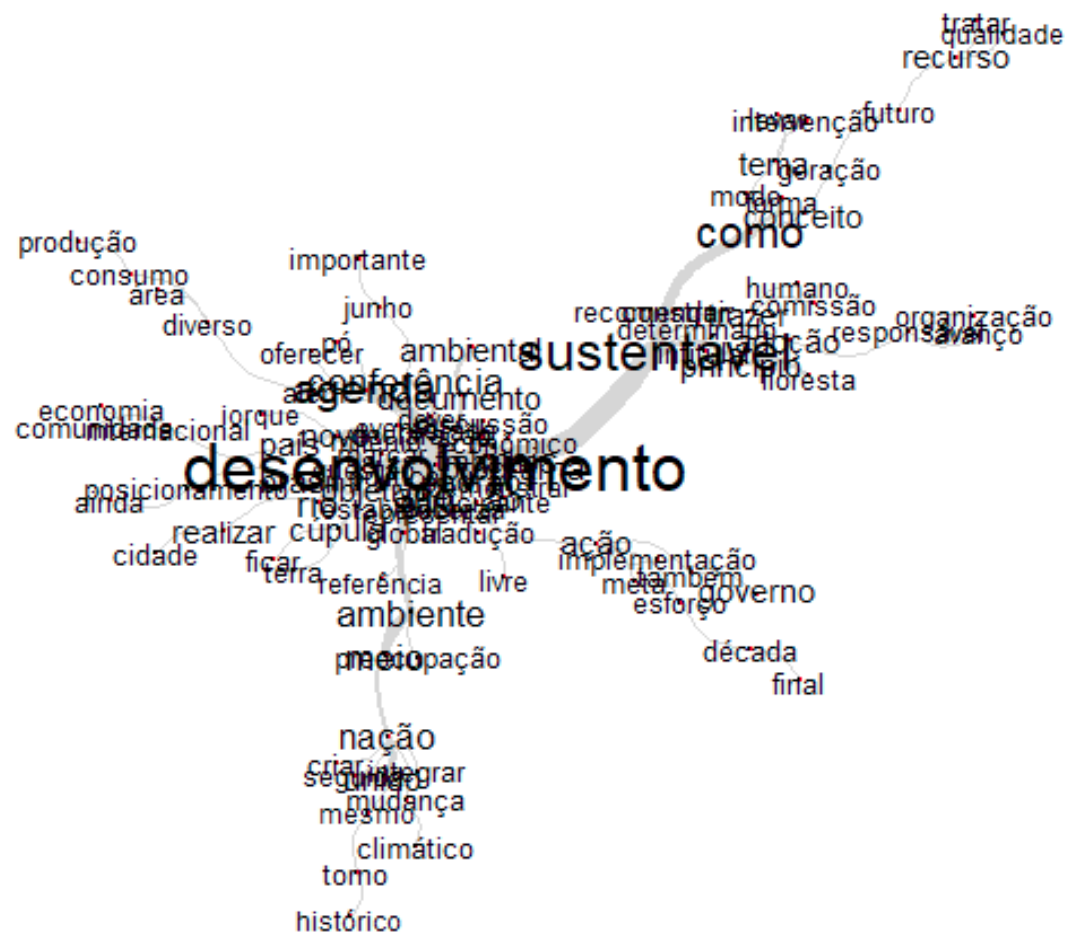

Fonte: Autoria própria.

\section{CONSIDERAÇÕES FINAIS}

O conceito de sustentabilidade vem sendo construído e debatido desde a década de 1970, passando por incorporação de adjetivos e criando um olhar contemporâneo para o desenvolvimento, que foi introduzido ao entendimento, de forma a dar origem ao desenvolvimento sustentável.

O Brasil trouxe e incorporou os avanços legislativos obtidos na discussão sobre o tema ao longo dos diferentes momentos históricos. Isso pode ser notado a partir da análise do arcabouço legal brasileiro, inclusive integrando a Carta Magna como marco decisivo de sua prática no país, caracterizando sua legislação sobre o assunto como uma das mais completas do mundo. Tais conceitos convergem e formam uma associação na atualidade, para o desenrolar de uma nova concepção de desenvolvimento econômico. 
No entanto, há de se notar que a incorporação da dimensão ambiental nas estratégias e nos projetos de crescimento econômico não é condição suficiente nem para o desenvolvimento sustentável, nem para a melhoria das condições de vida dos pobres e desprovidos, o que acaba por caracterizar uma limitação do presente artigo, uma vez que este viés não foi explorado.

Para que haja maior precisão acerca da congruência entre a prática de desenvolvimento sustentável e de desenvolvimento local, faz-se necessário o uso de um indicador associado a algum modelo de análise para verificar diretamente em um campo empírico como se dá tal relação. Isso demandaria adequada delimitação de recorte histórico, de escopo produtivo e de metodologia para mensurar seu grau de desenvolvimento econômico e testar a hipótese que relaciona a atividade local e a temática assinalada, o que abre uma possibilidade para estudos futuros.

\section{REFERÊNCIAS}

ALBAGLI, S. Globalização e espacialidade: o novo papel do local. In: CASSIOLATO, J. E.; LASTRES, H. M. M. (Ed.). Globalização e inovação localizada: experiências de sistemas locais no Mercosul. Brasília: IBICT, 1999.

BRANCO, S. M., Ecossistêmica: uma abordagem integrada dos problemas do meio ambiente. São Paulo: Ed. E. Blucher, 1989.

BRASIL. Portaria n. 81, de 11 de outubro de 2017. Aprova o Regimento Interno da ComissãoNacional para os Objetivos de Desenvolvimento Sustentável. Brasília-DF, 2017a. Disponível em: http://pesquisa.in.gov.br/imprensa/jsp/visualiza/index. jsp?data=13/10/2017\&jornal=1\&pagina=6\&totalArquivos=116. Acesso em: 19 abr. 2018.

BRASIL. Portaria n. 24, de 4 de abril de 2017. Brasília-DF, 2017b. Disponível em: http://www.secretariadegoverno.gov.br/acesso-a-informacao/licitacoescontratos-editais/secretaria-nacional-de-articulacao-social/portaria-comite-deselecao.pdf. Acesso em: 19 abr. 2018.

BRASIL. Decreto n. 8.892, de 27 de outubro de 2016. Brasília-DF, 2016. Disponível em: http://www.planalto.gov.br/ccivil_03/_ato2015-2018/2016/decreto/D8892. htm. Acesso em: 19 abr. 2018. 
BRASIL. Decreto n. 7.794, de 20 de agosto de 2012. Brasília-DF, 2012a. Disponível em: http://www.planalto.gov.br/ccivil_03/_ato2011-2014/2012/decreto/d7794. htm. Acesso em: 20 abr. 2018.

BRASIL. Decreto n. 7.746, de 5 de junho de 2012b. Brasília-DF, 2012b. Disponível em: http://www.planalto.gov.br/ccivil_03/_ato2011-2014/2012/decreto/d7746. htm. Acesso em: 20 abr. 2019. (a)

BRASIL. Lei n. 12.651, de 25 de maio de 2012c. Brasília-DF, 2012c. Disponível em: <http://www.planalto.gov.br/ccivil_03/_ato2011-2014/2012/lei/l12651.htm>. Acesso em: 19 abr. 2018. (c)

BRASIL. Decreto n. 7.390, de 9 de dezembro de 2010. Brasília-DF, 2010a. Disponível em: http://www.planalto.gov.br/ccivil_03/_ato2007-2010/2010/decreto/d7390. htm. Acesso em: 21 abr. 2018.

BRASIL. Lei n. 12.305, de 2 de agosto de 2010. Brasília-DF, 2010b. Disponível em: http://www.planalto.gov.br/ccivil_03/_ato2007-2010/2010/lei/l12305.htm. Acesso em: 19 abr. 2018.

BRASIL. Lei n. 12.187, de 29 de dezembro de 2009. Brasília-DF, 2009. Disponível em: http://www.planalto.gov.br/ccivil_03/_ato2007-2010/2009/Lei/L12187. htm\#art11. Acesso em: 21 abr. 2018.

BRASIL. Lei n. 9.605, de 12 de fevereiro de 1998. Brasília-DF, 1998. Disponível em: http://www.planalto.gov.br/CCivil_03/leis/L9605.htm. Acesso em: 19 abr. 2018.

BRASIL. Lei n. 9.433, de 8 de janeiro de 1997. Brasília-DF, 1997. Disponível em: http:/www.planalto.gov.br/ccivil_03/leis/I9433.htm. Acesso em: 19 abr. 2018.

BRASIL. Lei n. 8.666, de 21 de junho de 1993. Brasília-DF, 1993. Disponível em: http://www.planalto.gov.br/ccivil_03/Leis//8666cons.htm. Acesso em: 20 abr. 2018.

BRASIL. Lei n. 7.805, de 18 de julho de 1989. Brasília-DF, 1989. Disponível em: http://www.planalto.gov.br/ccivil_03/leis/L7805.htm. Acesso em: 19 abr. 2018.

BRASIL. Constituição da República Federativa do Brasil. Brasília-DF, 1988. Disponível em: http://www.planalto.gov.br/ccivil_03/constituicao/constituicao.htm. Acesso em: 18 abr. 2018. 
BRASIL. Lei n. 7.347, de 24 de julho de 1985. Brasília-DF, 1985. Disponível em: http://www.planalto.gov.br/ccivil_03/leis//7347orig.htm. Acesso em: 19 abr. 2018.

BRASIL. Lei n. 6.938, de 17 de janeiro de 1981. Brasília-DF, 1981. Disponível em: http://www.planalto.gov.br/ccivil_03/leis/L6938.htm. Acesso em: 19 abr. 2018.

BRASIL. Lei n. 6.766, de 19 de dezembro de 1979. Brasília-DF, 1979. Disponível em: http://www.planalto.gov.br/ccivil_03/leis/L6766.htm. Acesso em: 19 abr. 2018.

BRASIL. Ministério das Relações Exteriores. O Brasil e o desenvolvimento sustentável. Brasília-DF, [s.d.]. Disponível em: http://www.itamaraty.gov.br/pt-BR/politicaexterna/desenvolvimento-sustentavel-e-meio-ambiente/130-o-brasil-e-odesenvolvimento-sustentavel. Acesso em: 19 abr. 2018.

CÂMARA DOS DEPUTADOS. Agenda 21 - Conferência das Nações Unidas sobre o Meio Ambiente e Desenvolvimento. Brasília-DF: Câmara dos Deputados, 1995. Disponível em: http://www.onu.org.br/rio20/img/2012/01/agenda21.pdf. Acesso em: 19 abr. 2018.

DIXON, M. An Overview of Document Mining Technology. Review MIT, 1997.

FEINERER, I., HORNIK, K., MEYER, D. Text Mining Infrastructure. Journal of Statistical Software, p. 1-54, 2008.

HAIR, J. F., BLACK, W. C., BABIN, B. J., ANDERSON, R. E., TATHAM, R. L. Análise multivariada de dados. Bookman Editora, 2009.

MORAN, J. M.; ALMEIDA, A. E. B. Integração das Tecnologias na Educação/Secretaria de Educação a Distância. Brasília: Ministério da Educação, SEED, 2005. 204 p.

ORGANIZAÇÃO DAS NAÇÕES UNIDADAS. ECO-92. Brasília-DF: ONU, 1992a. Disponível em: https://nacoesunidas.org/?post_type=post\&s=eco+92. Acesso em: 20 abr. 2018.

ORGANIZAÇÃO DAS NAÇÕES UNIDAS. Declaração do Rio sobre Meio Ambiente e Desenvolvimento. Brasília-DF: ONU, 1992b. Disponível em http://www.onu.org. br/rio20/img/2012/01/rio92.pdf. Acesso em: 18 abr. 2018.

ORGANIZAÇÃO DAS NAÇÕES UNIDAS. A ONU e o meio ambiente. ONU, 2018. Disponível em: https://nacoesunidas.org/acao/meio-ambiente/. Acesso em: 19 abr. 2018. 
ORGANIZAÇÃO DAS NAÇÕES UNIDAS. Centro RIO+ mapeia posicionamento brasileiro sobre desenvolvimento sustentável em fóruns da ONU-2014. ONU, 2014. Disponível em: https://nacoesunidas.org/centro-rio-mapeia-posicionamentobrasileiro-sobre-desenvolvimento-sustentavel-em-foruns-da-onu/. Acesso em: 18 abr. 2018.

ORGANIZAÇÃO DAS NAÇÕES UNIDAS. Programa das Nações Unidas para o Meio Ambiente. ONU, 1972. Disponível em: https://legal.un.org/avl/ha/dunche/dunche. html/. Acesso em: 13 mar. 2018.

PAES, R. Estado da arte da discussão dos Objetivos de Desenvolvimento Sustentável no Brasil. Brasília-DF: ONUBR, 2018. Disponível em: https://nacoesunidas.org/ centro-rio-mapeia-posicionamento-brasileiro-sobre-desenvolvimento-sustentavelem-foruns-da-onu/. Acesso em: 19 abr. 2018.

PEGORARE, A. B.; MORAES, P. M.; MENDES, D. R. F.; OLIVEIRA, M. A. C.; COSTA, R. B.; MOREIRA, Tito B. S.; CUNHA, G. H. M. Spatial econometric analysis of the main agricultural commodities produced in Central-West Region, Brazil. African Journal of Agricultural Research, v. 13, p. 167-80, 2018.

RAMOS, T. B.; CAEIRO, S.; PIRES, S. M.; VIDEIRA, N. How are new sustainable development approaches responding to societal challenges? Sustainable Development: Springer, 2018.

SENADO FEDERAL. Meio ambiente e desenvolvimento sustentável. Brasília-DF: Senado Federal, 2018a. Disponível em: https://www12.senado.leg.br/institucional/ datasenado/materias/pesquisas/senado-ouve-populacao-brasileira-sobredesenvolvimento-sustentavel. Acesso em: 18 abr. 2018.

SENADO FEDERAL. O sucesso da Conferência Rio-92 da ONU e o desenvolvimento sustentável. Brasília-DF: Senado Federal, 2018b. Disponível em: http://www.senado. gov.br/noticias/Jornal/emdiscussao/rio20/a-rio20/o-sucesso-da-conferencia-rio92-da-onu-e-o-desenvolvimento-sustentavel.aspx. Acesso em: 19 abr. 2018.

TAN, A. Text mining: the state of the art and the challenges. In: WORKSHOP ON KNOWLEDGE DISOCOVERY FROM ADVANCED DATABASES, Pequim, China, 1999. Proceedings [...]. Pequim: PAKDD, 1999.

UNITED NATIONS. Convention on Biological Diversity. United Nations, 2018a. Disponível em: http://www.un.org/geninfo/bp/enviro.html. Acesso em: 18 abr. 2018. 
UNITED NATIONS. Convention to Combat Desertification. United Nations, 2018b. Disponível em: https://www2.unccd.int/. Acesso em: 18 abr. 2018.

UNITED NATIONS. Future we want. United Nations, 2018c. Disponível em: https:// sustainabledevelopment.un.org/rio20/futurewewant. Acesso em: 19 abr. 2018.

UNITED NATIONS. KP Introduction. United Nations, 2018d. Disponível em: https:// unfccc.int/process/the-kyoto-protocol. Acesso em: 18 abr. 2018.

UNITED NATIONS. Report of the united nations conference on environment and development. United Nations, 1992a. Disponível em: http://www.un.org/ documents/ga/conf151/aconf15126-3annex3.htm. Acesso em: 19 abr. 2018.

UNITED NATIONS. Report of the United Nations Conference on the Human Environment. United Nations Library: Stockholm, 1972. Disponível em: <https:// digitallibrary.un.org/record/523249/files/A_CONF.48_14_Rev.1-EN.pdf>. Acesso em: 19 abr. 2018.

UNITED NATIONS. Report of the World Comission on Environment and Development. United Nations, 1987. Disponível em: http://www.un.org/documents/ga/res/42/ ares42-187.htm. Acesso em: 19 abr. 2018.

UNITED NATIONS. United Nations Conference on Environment and Development (UNCED), Rio de Janeiro, 3-14 June 1992. United Nations, 1992b. Disponível em: https://www.un.org/en/conferences/environment/rio1992. Acesso em: 18 abr. 2018. 
